\title{
Local application of sodium salicylate enhances auditory responses in the rat's dorsal cortex of the inferior colliculus
}

\section{Chirag R. Patel and Huiming Zhang*}

Department of Biological Sciences, University of Windsor, Windsor, ON, Canada

\section{Edited by:}

Jinsheng Zhang, Wayne State

University, USA

\section{Reviewed by:}

Yiwen Zheng, University of Otago,

New Zealand

Hao Luo, Wayne State University, USA

Guang-Di Chen, State University of New York, USA

\section{*Correspondence:}

Huiming Zhang, Department of Biological Sciences, University of Windsor, 401 Sunset Avenue, Windsor, ON N9B 3P4, Canada e-mail: hzhang@uwindsor.ca
Sodium salicylate (SS) is a widely used medication with side effects on hearing. In order to understand these side effects, we recorded sound-driven local-field potentials in a neural structure, the dorsal cortex of the inferior colliculus $(\mathrm{ICd})$. Using a microiontophoretic technique, we applied SS at sites of recording and studied how auditory responses were affected by the drug. Furthermore, we studied how the responses were affected by combined local application of SS and an agonists/antagonist of the type-A or type-B $\gamma$ aminobutyric acid receptor ( $\mathrm{GABA}_{A}$ or $\mathrm{GABA}_{B}$ receptor). Results revealed that $\mathrm{SS}$ applied alone enhanced auditory responses in the ICd, indicating that the drug had local targets in the structure. Simultaneous application of the drug and a GABAergic receptor antagonist synergistically enhanced amplitudes of responses. The synergistic interaction between SS and a $\mathrm{GABA}_{A}$ receptor antagonist had a relatively early start in reference to the onset of acoustic stimulation and the duration of this interaction was independent of sound intensity. The interaction between SS and a $\mathrm{GABA}_{B}$ receptor antagonist had a relatively late start, and the duration of this interaction was dependent on sound intensity. Simultaneous application of the drug and a GABAergic receptor agonist produced an effect different from the sum of effects produced by the two drugs released individually. These differences between simultaneous and individual drug applications suggest that SS modified GABAergic inhibition in the ICd. Our results indicate that SS can affect sound-driven activity in the ICd by modulating local GABAergic inhibition.

Keywords: auditory system, $\mathrm{GABA}_{A}$ receptor, $\mathrm{GABA}_{B}$ receptor, hearing, midbrain, tinnitus, microiontophoresis

\section{INTRODUCTION}

Sodium salicylate (SS) is a widely used medication with side effects on hearing (1-5). The side effects include temporary hearing loss and transient tinnitus (6-11). In animal models, SS can cause conditioned behaviors as if experimental subjects perceived phantom sounds (12-19).

The effect of SS on hearing is likely related to changes caused by the drug in physiological processes in peripheral and central auditory structures [see Ref. $(5,20-22)$ for reviews]. In the auditory periphery, the drug can bind onto anion binding sites of the motor protein prestin (23). Such binding suppresses the electromotility of outer hair cells and reduces the output of the sensory organ (24-26). In spite of this reduction in the output, amplitudes of sound-driven local-field potentials (LFPs) in the central auditory structure, the inferior colliculus (IC), are not changed following systemic injection of SS $(22,27)$. The amplitudes of LFPs in the auditory cortex (AC) and the medial geniculate nucleus are even enhanced by the same drug manipulation $(16,22,27,28)$. These

Abbreviations: AC, auditory cortex; AMPA, $\alpha$-amino-3-hydroxy-5-methyl-4isoxazolepropionic acid; Bac, baclofen; BF, best frequency; BMI, bicuculline methiodide; $D_{N}$, negative deflection of a local-field potential; $D_{P}$, positive deflection of a local-field potential; GABA, $\gamma$-aminobutyric acid; IC, inferior colliculus; ICc, central nucleus of the inferior colliculus; ICd, dorsal cortex of the inferior colliculus; ICx, external cortex of the inferior colliculus; LFP, local-field potential; MT, minimum threshold (i.e., the threshold at the best frequency); Musc, muscimol; NMDA, $N$-methyl-D-aspartate; SS, sodium salicylate. findings suggest that SS can directly change physiological processes in the central auditory system, which compensates for the druginduced reduction in the output from the auditory periphery. In addition to sound-driven responses, spontaneous firing of neurons in structures such as the AC and the external cortex of the IC (ICx) can also be enhanced by systemic injection of SS (29-31). These results also suggest that the drug can directly affect physiological processes in central auditory structures. Existing results indicate that the effect of SS on auditory neural responses is predominantly restricted to non-lemniscal parts of the auditory system $(5,21,22)$.

In vitro neurophysiological/pharmacological methods have been used to investigate mechanisms through which SS affects neural activity. Experiments conducted in the AC, IC, hippocampal cornu ammonis area 1 (i.e., CA1 area), and spinal dorsal horn suggest that SS can affect inhibitory neurotransmission mediated by $\gamma$-aminobutyric acid (GABA) (32-35).

As the IC is a structure essential for hearing, it is significant to examine the effect of SS on auditory activities in the structure. There is evidence showing that GABAergic inhibition plays a major role in auditory responses in the IC (36-39) and SS can modulate GABAergic neurotransmission in the structure (34). Therefore, it is possible that the drug can change sound-driven responses in the structure through modulating local GABAergic neurotransmission. Area differences exist in the effect of SS on neural activity in the IC. For instance, while systemic injection of the drug leads to an enhancement in spontaneous activity in neurons in the ICx 
(29), it causes a reduction in spontaneous activity in neurons in a specific area of the central nucleus of the IC (ICc) (40).

The effect of SS on neural activities in the dorsal cortex of the IC (ICd) has not been evaluated so far. As a non-lemniscal part of the auditory midbrain, this structure has high levels of GABA (41-44) and GABAergic receptors (42, 45-50). Therefore, the present study was designed to investigate the effect of local SS on auditory responses in the ICd and to find whether such an effect was related to a change in local GABAergic inhibition. Sound-driven LFPs were recorded in the ICd. SS and a GABAergic receptor agonist/antagonist were released individually as well as simultaneously at sites of recording using a microiontophoretic technique. Our results indicate that local SS can enhance auditory responses in the ICd. Such enhancement is likely related to a modulation of GABAergic inhibition.

\section{MATERIALS AND METHODS ANIMAL PREPARATION}

Experiments were conducted using 26 male adult Wistar albino rats (Rattus norvegicus) with body weights between 250 and $500 \mathrm{~g}$. The rats were obtained from Charles River Canada Inc., Saint Constant, QC, Canada. Anesthesia was induced by combined injections of ketamine hydrochloride $(60 \mathrm{mg} / \mathrm{kg}$, i.m.) and xylazine hydrochloride $(10 \mathrm{mg} / \mathrm{kg}$, i.m.) and was maintained by supplemental injections of ketamine hydrochloride $(20 \mathrm{mg} / \mathrm{kg}$, i.m.) and xylazine hydrochloride $(3.3 \mathrm{mg} / \mathrm{kg}$, i.m.). Recordings were performed when a rat was inside a CL-15A LP single-wall soundattenuated booth (Eckel Industries, Morrisburg, ON, Canada). The rat's head was held firmly by a headbar attached to a Model 900 stereotaxic instrument (Kopf Instruments, Tujunga, CA, USA). A small craniotomy was made for placing an electrode assembly into the left ICd. Procedures were approved by the University of Windsor Animal Care Committee and were in accordance with the guidelines of the Canadian Council on Animal Care.

\section{ACOUSTIC STIMULATION}

Acoustic waveforms were generated digitally using a System 3 realtime signal processing system controlled by a personal computer running OpenEx software (Tucker-Davis Technologies, Alachua, FL, USA). Sounds were delivered to the ear contralateral to the recording site (i.e., the right ear) using a CF1 closed-field speaker (Tucker-Davis Technologies, Alachua, FL, USA) connected to a short piece of Tygon tubing inserted in the rat's external meatus. Brief monaural tone bursts with 2-ms rise/fall times (without a plateau) were used to elicit auditory responses. The soundgenerating system was calibrated over a frequency range between 100 and $45,000 \mathrm{~Hz}$ using a 7017 condenser microphone (ACO pacific, Belmont, CA, USA).

\section{ELECTRODES FOR PHYSIOLOGICAL RECORDINGS AND PHARMACOLOGICAL MANIPULATIONS}

A piggy-back electrode assembly as described in a previous publication (51) was used in experiments. The single-barrel recording electrode (impedance $300-500 \mathrm{k} \Omega$ ) of the assembly was filled with either $2 \mathrm{M} \mathrm{NaCl}$ or 3\% N-(2-aminoethyl) biotinamide hydrochloride (Neurobiotin, Vector Laboratories SP-1120, Burlingame, CA, USA) in $0.5 \mathrm{M}$ sodium acetate.
Of the five barrels of the drug-releasing pipette, one was filled with SS (50 mM, pH 3.5, Sigma-Aldrich S3007, Oakville, ON, Canada). The second and third barrels were filled with bicuculline methiodide (BMI, 25 mM, pH 3.5, Sigma-Aldrich B6889, Oakville, ON, Canada), an antagonist for the type-A GABAergic receptor $\left(\mathrm{GABA}_{\mathrm{A}}\right.$ receptor), and CGP35348 (25 mM, pH 3.5, Sigma-Aldrich C5851, Oakville, ON, Canada), an antagonist for the type-B GABAergic receptor $\left(\mathrm{GABA}_{\mathrm{B}}\right.$ receptor). Alternatively, the two barrels were filled with the $\mathrm{GABA}_{\mathrm{A}}$ receptor agonist muscimol (Musc, 10 mM, pH 3.5, Sigma-Aldrich M1523, Oakville, ON, Canada) and the $\mathrm{GABA}_{\mathrm{B}}$ receptor agonist baclofen $(\mathrm{Bac}, 10 \mathrm{mM}$, pH 3.5, Sigma-Aldrich B5399, Oakville, ON, Canada), respectively. The remaining barrels were filled with $165 \mathrm{mM} \mathrm{NaCl}$. The vehicle of Bac was a citrate buffer, while that of the other drugs was $165 \mathrm{mM} \mathrm{NaCl}$. Drugs were released iontophoretically using a Neurophore $\mathrm{BH}-2$ microiontophoresis system (Harvard Apparatus, Saint Laurent, QC, USA).

\section{EXPERIMENTAL PROCEDURES}

An electrode assembly was driven into the left ICd from a dorsorostro-lateral to a ventro-caudo-medial location of the brain [see Ref. (51, 52) for details] using a model 2660 micropositioner (Kopf, Tujunga, CA, USA). A - $20 \mathrm{nA}$ retention current was applied to each barrel with a pharmacological agent when the electrode assembly was in the brain. Neural signals were amplified by a 2400 A preamplifier (Dagan, Minneapolis, MN, USA) and sampled at $24.414 \mathrm{kHz}$ using the System 3 real-time signal processing system.

For each rat, sound-evoked LFPs were recorded at a single site. Trains of contralaterally presented tone bursts were used to search for a site where large LFPs could be elicited. Each train had 9 tone bursts with their frequencies equally spaced on a logarithmic scale. The 9 tone bursts were presented in a randomized order at a constant rate of 4/s and a fixed level of $70 \mathrm{~dB}$ SPL. A sound-evoked LFP had a relatively small positive deflection $\left(D_{P}\right)$ followed by a large negative deflection $\left(D_{N}\right)$ (see Figure 1A, for example). The total duration of the response was about $40 \mathrm{~ms}$. Upon identification of a recording site, trains of tone bursts with reduced sound-pressure levels and frequency ranges were used to determine the best frequency (BF) and the threshold at BF (i.e., the minimum threshold or MT) at this site.

An LFP in response to a BF tone burst was recorded at the MT and multiple sub- and supra-threshold sound-pressure levels. Peak amplitude by sound-pressure-level functions and peak latency by sound-pressure-level functions were created for the $\mathrm{D}_{\mathrm{P}}$ and $\mathrm{D}_{\mathrm{N}}$ of an LFP. A tone burst was presented 300 times at each level for producing an averaged evoked LFP. Tone burst presentations (Total number: number of levels $\times 300$ ) were produced in a randomized order at a rate of $4 / \mathrm{s}$.

An LFP was also recorded at multiple (typically 9) frequencies at a fixed sound-pressure level at $10-30 \mathrm{~dB}$ above the MT. These frequencies were evenly spaced on a logarithmic scale, with the middle frequency equal to the BF and the range covering the frequency response area of the recording site. Peak amplitude by sound-frequency functions and peak latency by sound-frequency functions were created for the $D_{P}$ and $D_{N}$ of an LFP. A tone burst was presented 300 times at each frequency for generating 


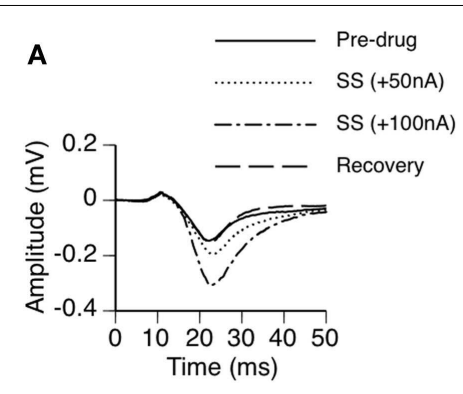

B

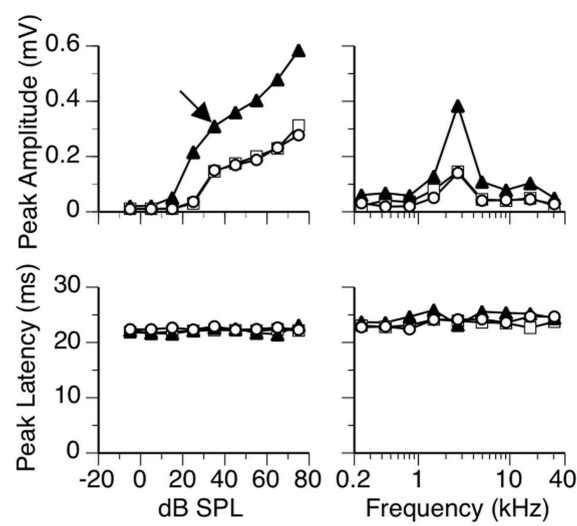

FIGURE 1 |An example showing the effect of SS on an LFP recorded in the ICd. (A) Left panel: LFPs evoked by a tone burst at the BF $(2.7 \mathrm{kHz})$ and $10 \mathrm{~dB}$ above the MT of the recording site [as indicated by an arrow in the top left panel of (B)] before, during, and after application of SS. (A) Right panel: an LFP evoked by the same sound when a microiontophoretic current of $100 \mathrm{nA}$ (the maximum current used in drug release in this case) was applied to an electrode barrel containing saline vehicle alone. LFPs recorded before
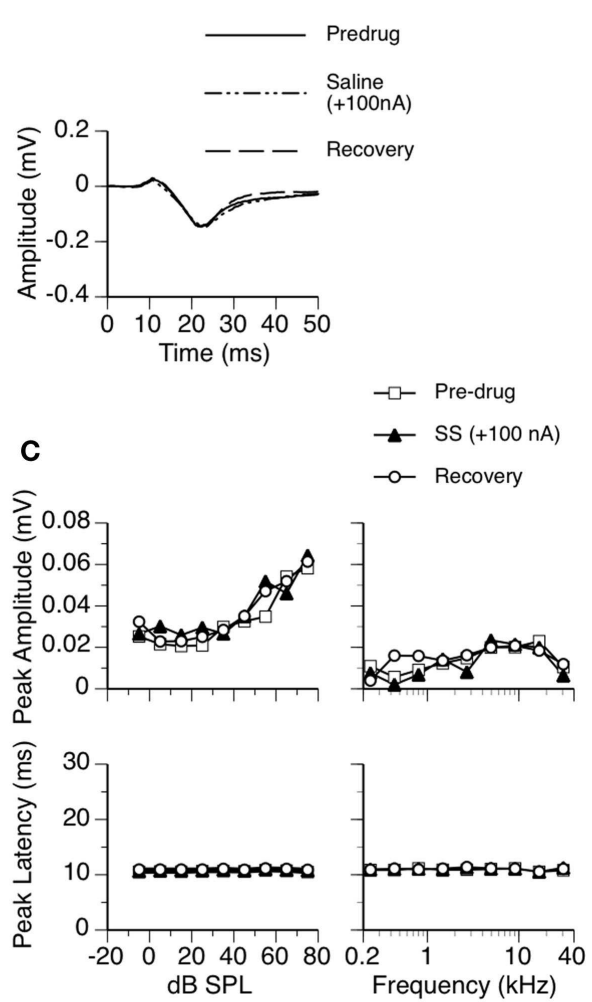

application of SS and after recovery are also shown in the panel. $\mathbf{( B , C )}$ Dependences of the peak amplitude (upper panels) and the peak latency (bottom panels) of the $D_{N}(\mathbf{B})$ and the $D_{P}(\mathbf{C})$ on the sound-pressure level (left panels) and sound frequency (right panels). In both (B,C), results shown in the left panels were obtained at the BF of the recording site. Results shown in the right panels were obtained at $20 \mathrm{~dB}$ above the MT of the recording site.

indeed caused by drugs but not electrical currents. These recordings were conducted after effects of SS and agonists/antagonists were examined and auditory responses fully returned to pre-drug levels. Results from each of the nine cases indicated that microiontophoretic currents did not change the waveform of an LFP. The right panel of Figure 1A shows an example of an LFP recorded when a current was applied to an electrode barrel containing vehicle alone.

In spite of the fact that our stereotaxic coordinates result in consistent placement of an electrode in the ICd (51), the site of recording in the ICd was verified in two randomly chosen rats in the present study. Following physiological recordings, neurobiotin was released using a microiontophoretic current $(5 \mu \mathrm{A}, 7$-s on/off times, total duration 15-25 min) generated by a Midgard Precision Current Source (Stoelting, Wood Dale, IL, USA). Twenty minutes after the completion of drug release, the rat was given an overdose of sodium pentobarbital $(120 \mathrm{mg} / \mathrm{kg}$, i.p. $)$ and transcardially perfused with $4 \%$ paraformaldehyde. After the brain was extracted, it was cryoprotected in $30 \%$ sucrose for overnight. It was then frozen sectioned at $40 \mu \mathrm{m}$ in the frontal plane using a CM1050 S cryostat (Leica Microsystems, Heidelberg, Germany). An immunohistological reaction was conducted by using streptavidin-Alexa 
Fluor 568 conjugate (Molecular Probes, Eugene, OR, USA) and the labeling was examined using a CTR 6500 microscope (Leica Microsystems).

\section{DATA ANALYSIS}

The effect of a drug/drugs was evaluated by comparing the peak amplitude and latency of a deflection $\left(D_{N}\right.$ or $\left.D_{P}\right)$ obtained before and during application of the drug/drugs. A difference waveform between the LFPs recorded during and before drug application was used to evaluate the time course of drug-inducted changes.

A change in the amplitude of LFP caused by simultaneous application of SS and a receptor agonist/antagonist was compared with the sum of the changes caused by the two drugs applied individually. A disparity between simultaneous and individual applications in the total effect of the drugs was used to indicate an interaction between the two drugs during simultaneous application. Such interaction would suggest that a modulation of GABAergic pathways/neurotransmission by SS. A larger total effect during simultaneous application would indicate a synergistic interaction between two drugs (53).

Statistical analysis was conducted by using IBM SPSS Statistics 22 and a custom-made script based on MatLab and Simulink (R2008b).

\section{RESULTS}

The effect of SS on sound-driven LFPs was studied in all the 26 rats (named as cases elsewhere in the text) used in this study. In a subgroup of nine cases, we examined effects of BMI applied individually and in combination with SS. In a subgroup of eight cases, we examined effects of CGP35348 applied individually and in combination with SS. There were seven cases used in both the groups. For each of the seven cases, effects of BMI (alone and in combination with SS) were examined first. Effects of CGP35348 (alone and in combination with SS) were examined after an LFP completely recovered from effects of BMI and SS. Effects of Musc and Bac (each applied individually and in combination with SS) were investigated in two separate subgroups with six and seven cases, respectively. Effects of GABAergic receptor agonists/antagonists (alone and in combination with SS) were not tested in the remaining three cases.

\section{EFFECTS OF SS ON LFPs IN THE ICd}

Sodium salicylate increased the amplitude of an LFP over the duration of the $\mathrm{D}_{\mathrm{N}}$ in a current-dependent manner. For the example shown in Figure 1, the peak amplitude was increased by about $50 \%$ when SS was released at $50 \mathrm{nA}$ and was more than doubled at $100 \mathrm{nA}$ (Figure 1A left panel). The increase in the peak amplitude of $D_{N}$ was observed over a wide range of intensities and frequencies (Figure 1B top panels). The peak latency of $\mathrm{D}_{\mathrm{N}}$ was not affected by the drug (Figures 1A,B bottom panels). The $\mathrm{D}_{\mathrm{N}}$ typically restored its pre-drug shape about $20 \mathrm{~min}$ after the cessation of drug release (Figures 1A,B), indicating that the effect of SS was reversible.

The effect of SS on the peak amplitude of an LFP was examined at 10,20 , and $30 \mathrm{~dB}$ above the MT in each of the 26 cases. Group results indicated that the effect of SS was significant [Figure 2A; two-way repeated-measures ANOVA, $\left.F_{(1,25)}=24.28, p<0.001\right]$. Post hoc analysis revealed that the increase caused by the drug was significant at all intensities (Tukey pairwise comparisons with Bonferroni correction, $p<0.001$ at all intensities). No statistical differences existed between the peak latencies of the $D_{N}$ recorded before and during the drug (Figure 2B).

The waveform of $D_{P}$ including its peak amplitude and latency was not affected by SS (see Figures 1A,C, for example). Thus, no further analyses were conducted on this deflection.

We examined the time window over which SS significantly increased the amplitude of an LFP (Figure 3). At each specific stimulus level, two LFPs recorded before and during application of SS were paired for each of the 26 cases. The resulting 26 pairs of LFPs were used to generate two grand-mean waveforms (top panels in Figures 3A-C). Each waveform (either a recorded trace or a grand mean) had 6104 data points, as a recording was conducted over a $250 \mathrm{~ms}$ period at a sampling rate of $24.414 \mathrm{kHz}$. A Wilcoxon signed-rank test was conducted at each of these 6104 points using 26 pairs of amplitude values obtained before and during application of SS. A resulting $p$-value was used to indicate the level of significance of the change caused by SS at this sampling point. A
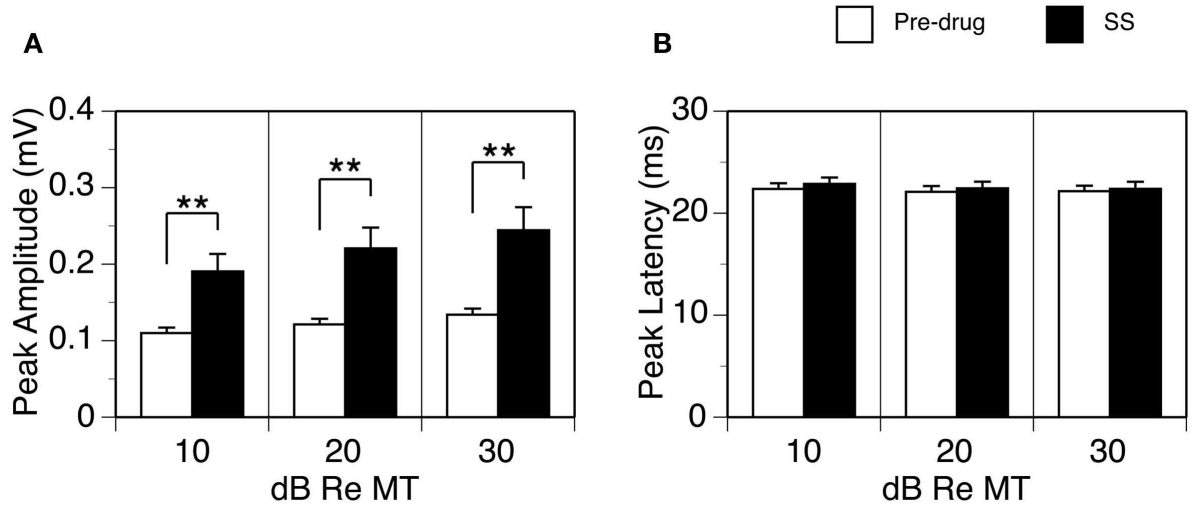

FIGURE 2 | Group results $(\boldsymbol{n}=\mathbf{2 6})$ showing effects of SS on the peak amplitude $(A)$ and peak latency of the $D_{\mathbf{N}}(B)$. For making $(A, B)$, data from each animal were collected at the BF and 10,20 , and $30 \mathrm{~dB}$ above the MT of a recording sites. Double stars indicate statistical significance at the level of $p<0.001$. Error bars represent SE. 


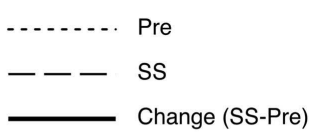

A

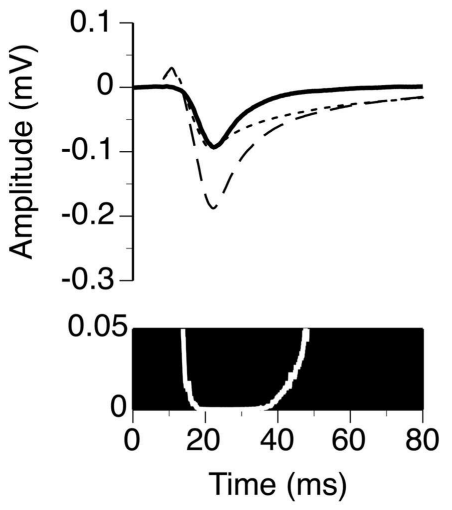

FIGURE 3 | Group results $(n=26)$ showing the time window over which SS enhances the amplitude of an LFP recorded at the BF of the recording site. (A-C) are based on LFPs recorded at 10, 20, and $30 \mathrm{~dB}$ above the MT of a recording site. In the upper panels of (A-C), dotted and dashed lines represent grand-mean waveforms of

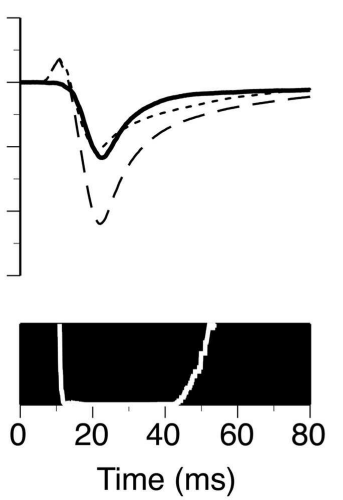

C

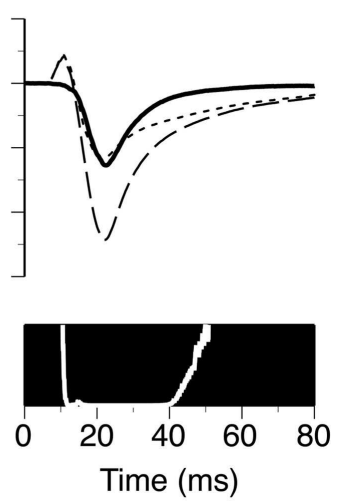

LFPs recorded before and during SS, respectively. A solid black line is the difference between two grand-mean waveforms. A white line with a black background is a $p$-value (Wilcoxon signed-rank test) by time function comparing the difference between the amplitudes of the two grand-mean waveforms. $p$-value by time curve obtained at $10 \mathrm{~dB}$ above the MT indicated that SS significantly increased the amplitude of an LFP $(p<0.05)$ at all points over a time window between 13.8 and $48.1 \mathrm{~ms}$ after the onset of a stimulus (bottom panel in Figure 3A). This time window was to some extent wider at higher stimulus levels (compare Figures 3B,C bottom panels with the Figure 3A bottom panel).

\section{INTERACTIONS BETWEEN SS AND GABAergic RECEPTOR ANTAGONISTS IN SHAPING LFPS}

In nine cases, sound-driven LFPs were recorded when SS was released along with the $\mathrm{GABA}_{\mathrm{A}}$ receptor antagonist BMI. For the example shown in Figure 4, the peak amplitude of the $D_{N}$ at $20 \mathrm{~dB}$ above the MT was increased by SS (released at $100 \mathrm{nA}$ ) and BMI (released at $20 \mathrm{nA}$ ) by about 140 and $120 \%$, respectively (Figure 4A). Simultaneous application of the two drugs resulted in an increase in peak amplitude by more than $530 \%$ (Figure 4A), which was much larger than the sum of the increases caused by the two drugs individually (a total of $260 \%$ ). This disparity suggested that a synergistic interaction existed between SS and BMI in regulating an LFP. Such an interaction was observed over a wide range of intensities and frequencies (Figure 4B). Effects of SS and BMI peaked at almost the same time (Figure 4A). Nevertheless, the effect of SS lasted longer than that of BMI.

Group results from nine cases (Figure 5A) confirmed findings from the example shown in Figure 4. As results under different drug conditions (i.e., control, SS alone, SS + BMI, and BMI alone) were obtained from the same nine animals over time, a two-way repeated-measures ANOVA was used for analyzing these results. An interaction between the two group factors SS and BMI was examined. At $10 \mathrm{~dB}$ above the MT, SS, and BMI released individually caused significant increases in the peak amplitude of the
$\mathrm{D}_{\mathrm{N}}\left[F_{(1,8)}=106.79, p<0.001\right.$ for SS; $F_{(1,8)}=23.14, p<0.005$ for $\mathrm{BMI}]$. The two drugs released simultaneously caused an increase larger than the sum of the increases caused by the two drugs applied individually $\left[F_{(1,8)}=8.631, p<0.05\right]$. Results obtained at other supra-threshold intensities were consistent with those obtained at $10 \mathrm{~dB}$ above the MT. Neither individual nor combined application of SS and BMI changed the peak latency of the $D_{N}$ (Figure 5B).

We examined the time window over which SS and BMI had a synergistic interaction in regulating LFPs. Two waveforms were formed at each sound-pressure level $(10,20$, or $30 \mathrm{~dB}$ above the MT) for each case. One was a difference waveform between the LFPs obtained before and during simultaneous application of SS and BMI (reflecting a total increase caused by the drugs applied simultaneously). The other one was the sum of the two difference waveforms resulting from individual applications of the drugs (reflecting a total increase caused by the drugs applied individually). Pairs of these waveforms from nine individual cases were utilized to generate two grand-mean waveforms (Figures 6A-C upper panels). At each of the 6104 sampling points $(250 \mathrm{~ms}$ recording trace sampled at $24.414 \mathrm{kHz}$ ), we examined the disparity between the total increase caused by SS and BMI applied simultaneously and the total increases caused by the drugs applied individually (Wilcoxon signed-rank test, data from nine cases). Such a disparity was used to reflect a synergistic interaction between SS and BMI. At $10 \mathrm{~dB}$ above the MT, a disparity $(p<0.05)$ existed at all sampling points within a time window between 13.8 and $26.1 \mathrm{~ms}$ after the onset of a stimulus (Figure 6A). Similar time windows of interaction were observed at 20 and $30 \mathrm{~dB}$ above the MT (13.126.2 and $13.4-26.2 \mathrm{~ms}$ after the onset of a stimulus, respectively) (Figures 6B,C). 

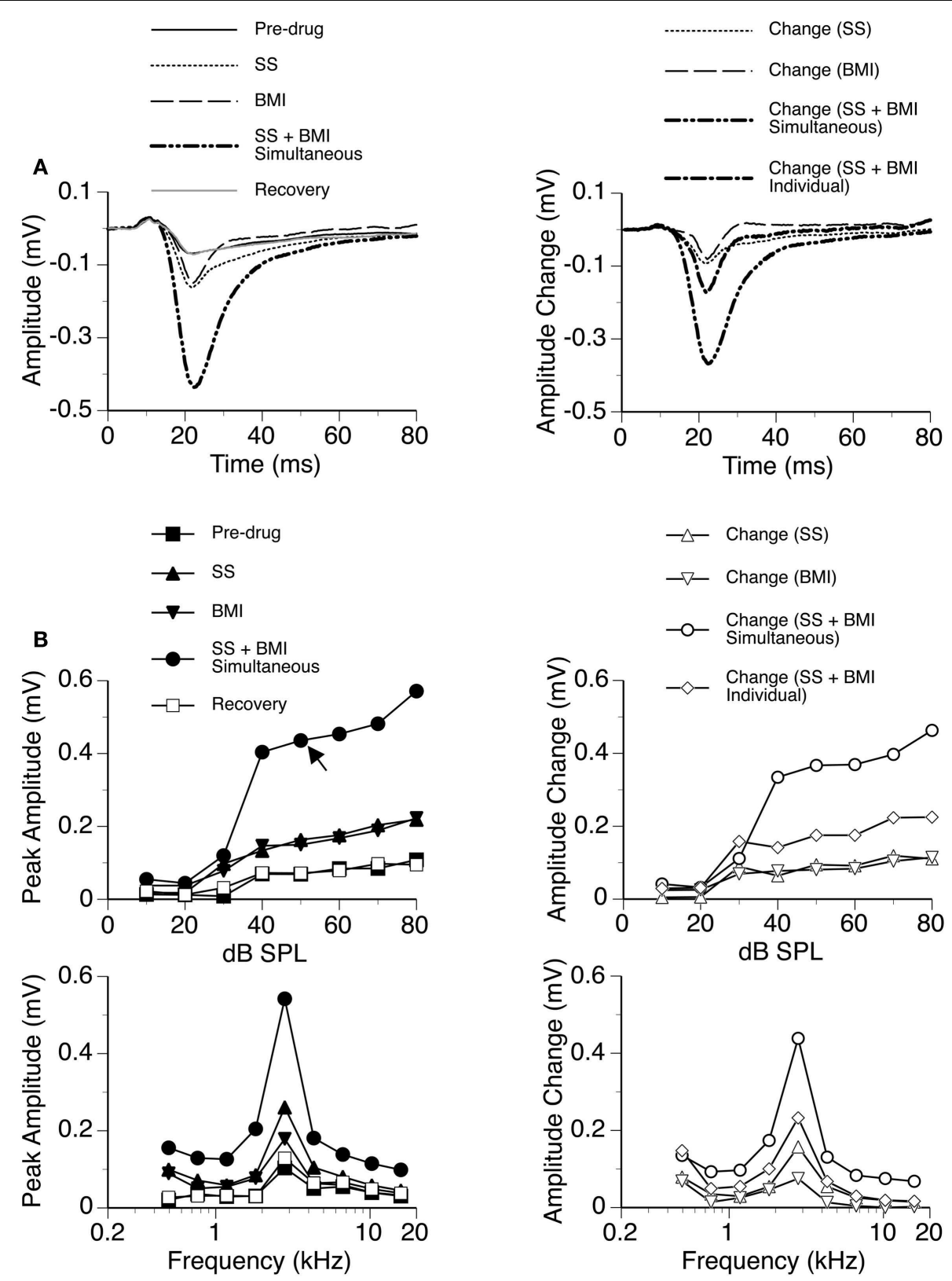

FIGURE 4 |An example showing the interaction between SS and BMI (A) Left panel: LFPs evoked by a tone burst at the BF $(2.8 \mathrm{kHz})$ and $20 \mathrm{~dB}$ above the MT of a recording site [as indicated by an arrow in the top left panel of (B)] before drug, during individual and simultaneous applications of SS and $\mathrm{BMI}$, and after recovery. (A) Right panel: difference waveforms showing changes caused by individual and simultaneous applications of SS and BMI. Also, shown in this panel is a waveform resulting from summation of changes caused by individual applications of SS and BMI. (B) Left panels: amplitude by sound-pressure level (top) and amplitude by sound-frequency (bottom) functions of the $D_{N}$ obtained before drug, during individual and simultaneous applications of SS and BMI, and after recovery. (B) Right panels: changes in the peak amplitude of the $D_{N}$ caused by individual and simultaneous applications of SS and BMI at various sound-pressure levels (top) and sound frequencies (bottom). Also, shown in each of the right panels in (B) is a curve resulting from summation of changes caused by individual applications of SS and BMI.
In eight cases, recordings were conducted when $\mathrm{SS}$ was released along with the $\mathrm{GABA}_{\mathrm{B}}$ receptor antagonist CGP35348. While SS produced a large increase in the amplitude of the $\mathrm{D}_{\mathrm{N}}$, the increase caused by CGP35348 was moderate (Figure 7). These effects of the drugs were observed over a wide range of sound intensities and frequencies. The two drugs applied simultaneously produced an increase much larger than the sum of the increases caused by the two drugs applied individually, suggesting that SS and CGP35348 enhanced an LFP synergistically.

Group results from eight cases (Figure 8A) confirmed findings from the example shown in Figure 7. At $10 \mathrm{~dB}$ above the MT, individual applications of SS and CGP35348 caused significant 


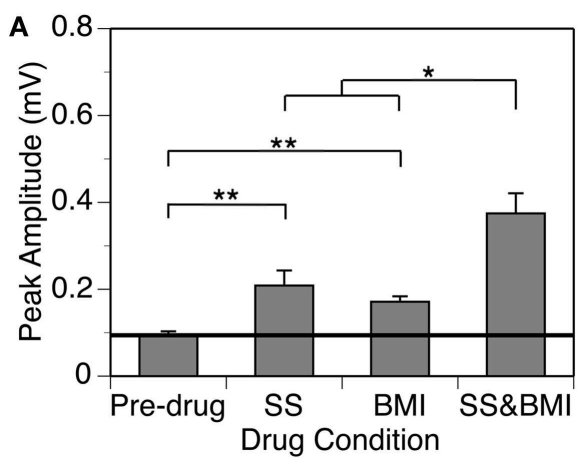

FIGURE 5 | Group results $(n=9)$ obtained at $10 \mathrm{~dB}$ above the MT showing effects of individual applications of SS and BMI (two middle bars) and a simultaneous application of the drugs (the right bar) on the peak amplitude $(A)$ and the peak latency $(B)$ of the $D_{N}$. The horizontal line

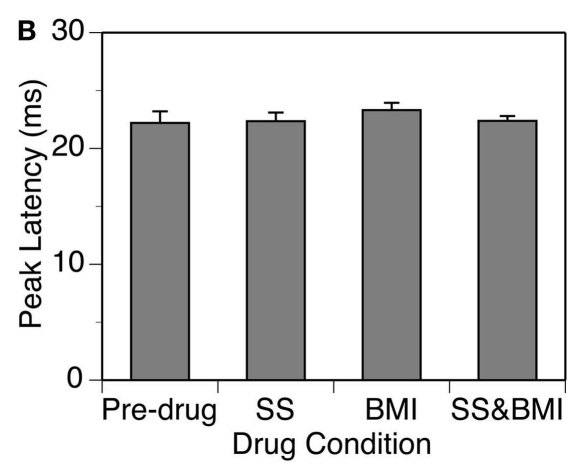

in (A) represents the mean peak amplitude of the $D_{N}$ obtained before drug application. Double stars indicate statistical significance at the level of $p<0.005$. A single star indicates statistical significance at the level of $p<0.05$. Error bars represent SE.
A

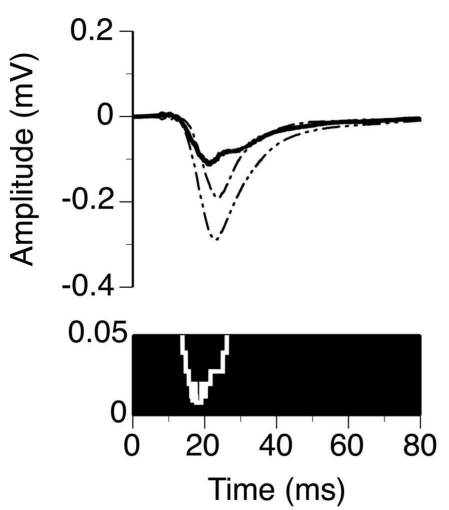

B

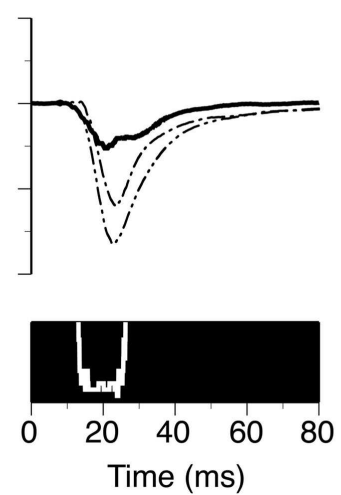

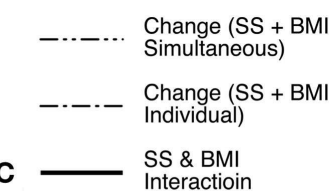
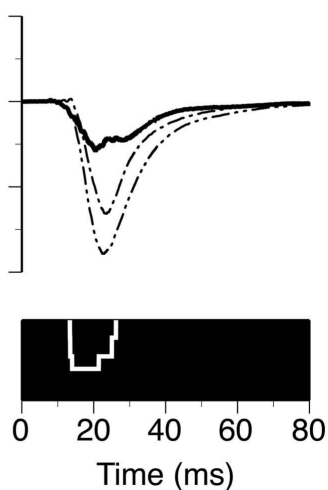

FIGURE 6 | Group results $(n=9)$ showing time windows over which a synergistic interaction exists between SS and BMI in enhancing the amplitude of an LFP recorded at the BF of a recording site. (A-C) are

based on results obtained at 10,20 , and $30 \mathrm{~dB}$ above the MT of a recording site. In (A-C), a white line with a black background in the bottom panel is a $p$-value by time function showing statistical significance of the difference between the total changes caused by individual and simultaneous applications of SS and BMI. increases in the peak amplitude of the $D_{N}$, while simultaneous application of the drugs caused an increase much larger than the sum of those caused by individual applications of the drugs [two-way repeated-measures ANOVA, $F_{(1,7)}=49.99, p<0.001$ for SS; $F_{(1,7)}=22.17, p<0.005$ for CGP35348; $F_{(1,7)}=6.78, p<0.05$ for the interaction between drugs]. Results obtained at other supra-threshold sound-pressure levels were consistent with those obtained at $10 \mathrm{~dB}$ above the MT. Group results indicated that SS and CGP35348 did not affect the peak latency of the $D_{N}$ (Figure 8B).

Using results from the eight cases and the same method as used for analyzing results presented in Figure 6, we evaluated the time window over which SS and CGP35348 had a synergistic interaction in regulating the amplitude of an LFP (Figure 9). At $10 \mathrm{~dB}$ above the MT, an interaction was observed at each time point over a time window between 20.0 and $27.6 \mathrm{~ms}$ after the onset of stimulation (Wilcoxon signed-rank test, $p<0.05$ ). This time window of interaction was increased to $19.2-29.3$ and $18.8-33.1 \mathrm{~ms}$ at 20 and $30 \mathrm{~dB}$ above the MT, respectively (Wilcoxon signed-rank test at each data point, $p<0.05)$.

\section{INTERACTIONS BETWEEN SS AND GABAergic RECEPTOR AGONISTS IN SHAPING LFPs}

Sodium salicylate was released in combination with the $\mathrm{GABA}_{\mathrm{A}}$ receptor agonist Musc in six cases, as shown by an example in Figure 10. Musc consistently suppressed the $D_{N}$ of an 


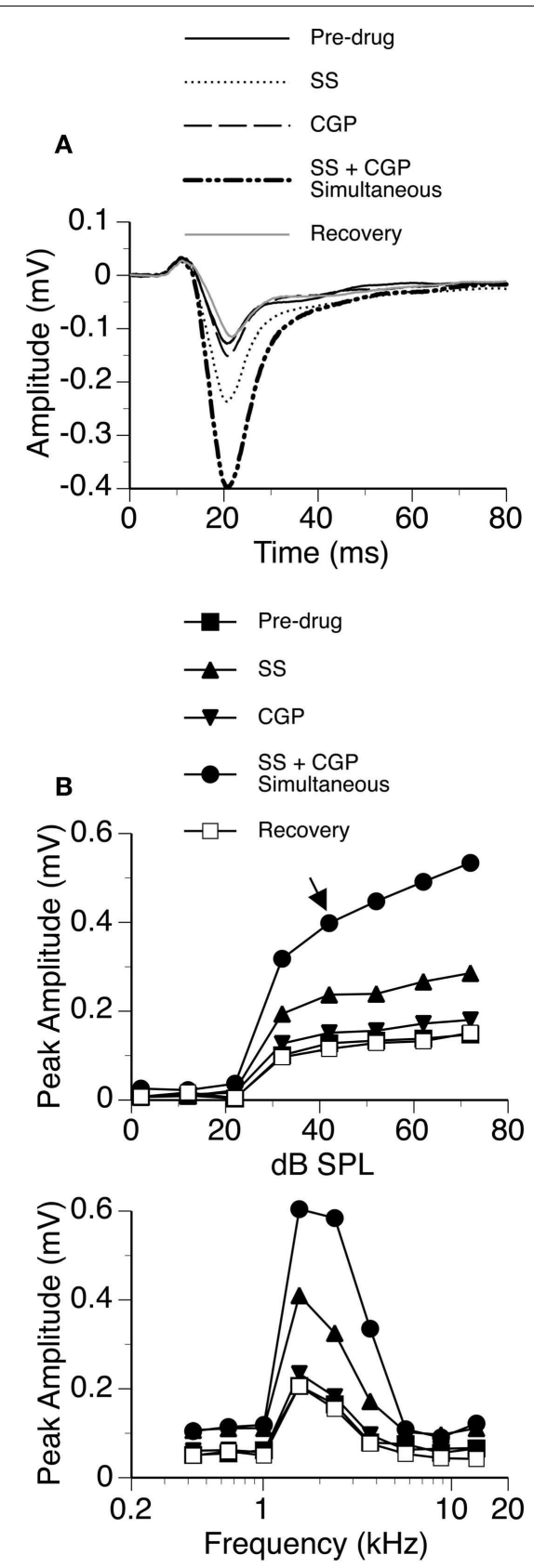

FIGURE 7 | An example showing the interaction between SS and CGP35348. (A) Left panel: LFPs evoked by a tone burst at the BF $(2.4 \mathrm{kHz})$ and $20 \mathrm{~dB}$ above the MT of a recording site [as indicated by an arrow in the top left panel of (B)] before drug, during individual and simultaneous applications of SS and CGP35348, and after recovery. (A) Right panel: difference waveforms showing changes caused by individual and simultaneous applications of SS and CGP35348. Also, shown in this panel is a waveform resulting from summation of changes caused by individual applications of SS

LFP while SS consistently enhanced it when the drugs were released individually. During simultaneous application of the two drugs, the waveform of the $\mathrm{D}_{\mathrm{N}}$ always fell between the waveforms obtained during individual applications of the drugs (e.g., Figure 10A left panel). The change caused by the drugs released

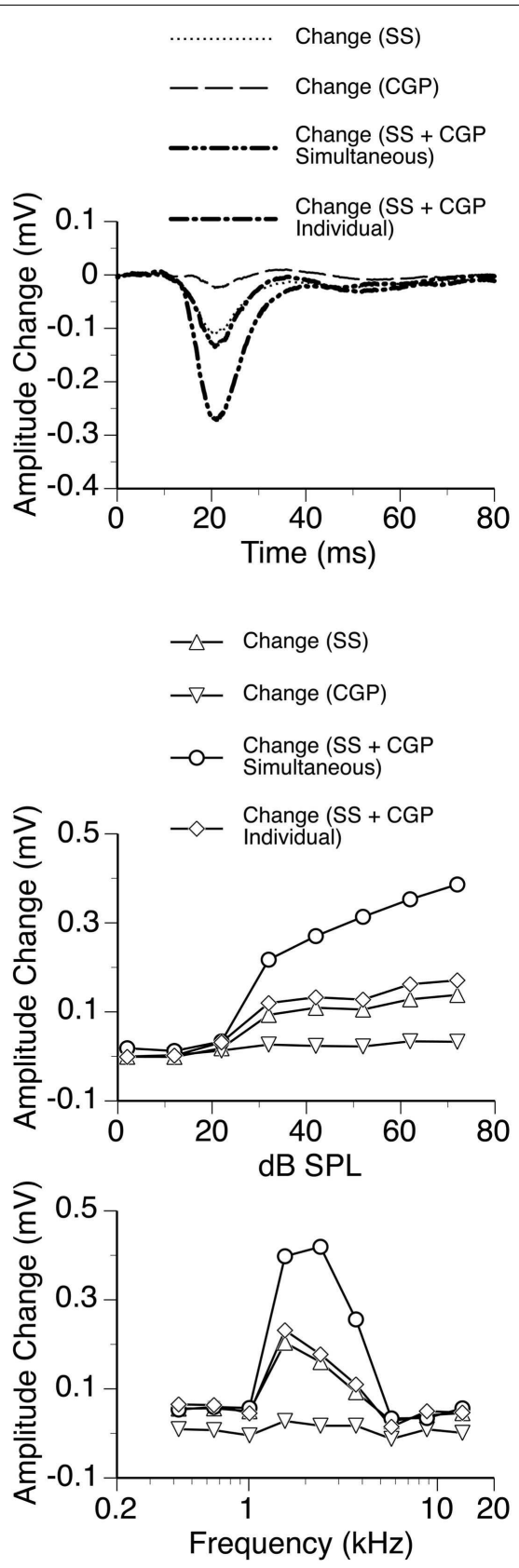

and CGP35348. (B) Left panels: amplitude by sound-pressure level (top) and amplitude by sound-frequency (bottom) functions obtained before drug, during individual and simultaneous applications of SS and CGP35348, and after recovery. (B) Right panels: changes in the peak amplitude of an LFP caused by individual and simultaneous applications of SS and CGP35348 at various sound-pressure levels (top) and sound frequencies (bottom). Also, shown in each of the right panels of $(\mathbf{B})$ is a curve resulting from summation of changes caused by individual applications of the drugs.

simultaneously was different from the sum of the changes caused by the drugs released individually (Figure 10A right panel), suggesting that the drugs interacted with each other in regulating a response. SS-induced enhancement and Musc-induced suppression were observed over a wide range of sound intensities; 


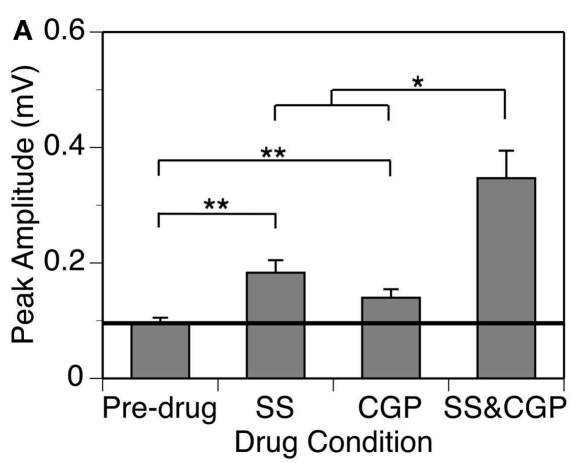

FIGURE 8 | Group results $(n=8)$ obtained at $10 \mathrm{~dB}$ above the MT showing effects of individual applications of SS and CGP35348 (two middle bars) and a simultaneous application of the drugs (right bar) on the peak amplitude $(A)$ and latency $(B)$ of the $D_{N}$. A horizontal line in

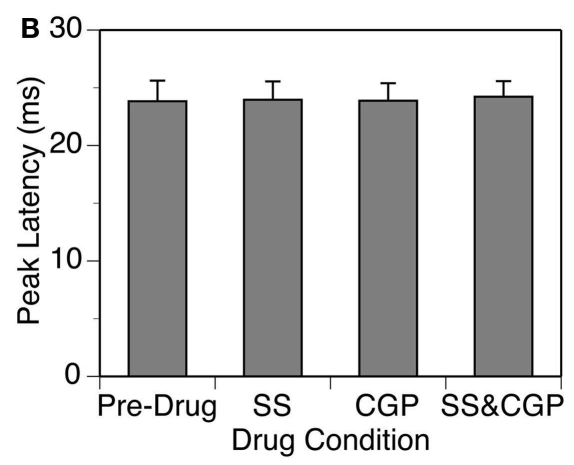

(A) represent the mean peak amplitude of the $D_{N}$ obtained before drug application. Double stars indicate statistical significance at the level of $p<0.005$. A single star indicates statistical significance at a level of $p<0.05$. Error bars represent SE.

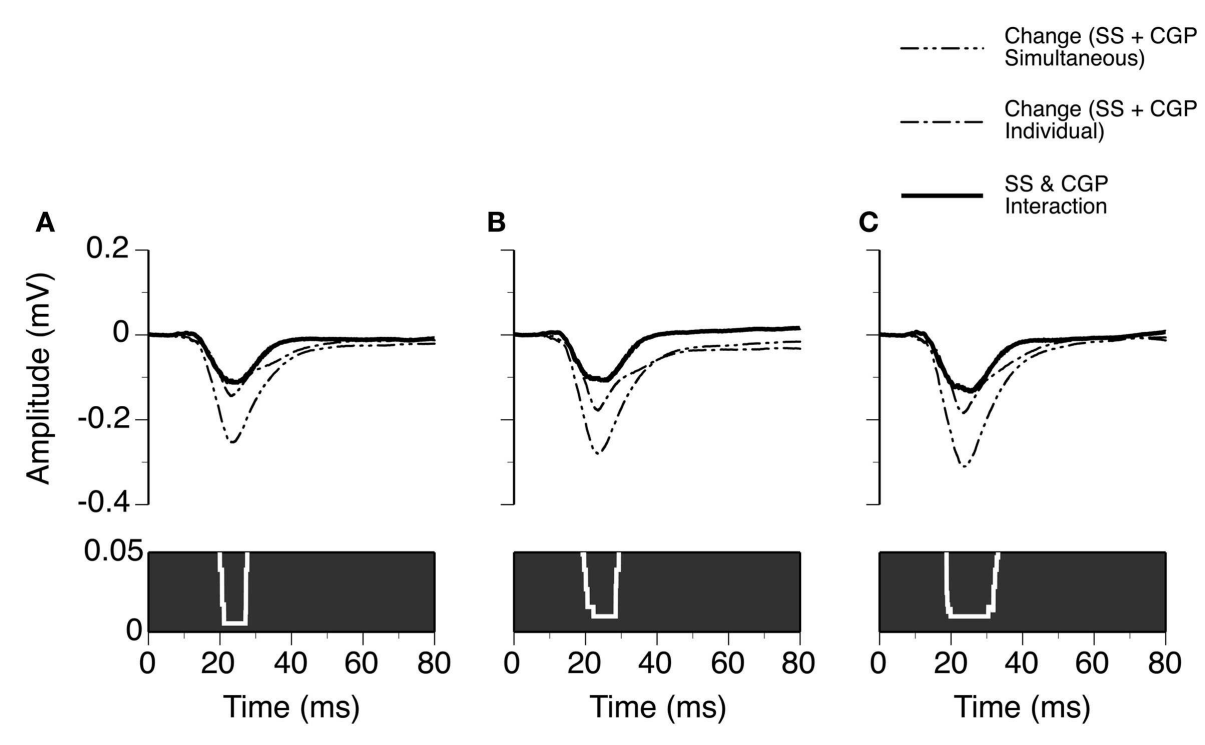

FIGURE 9 | Group results $(n=8)$ showing the time window over which a synergistic interaction exists between SS and CGP35348 in enhancing the amplitude of an LFP recorded at the $B F$ of a recording site. (A-C) are results obtained at 10,20 , and $30 \mathrm{~dB}$ above the $\mathrm{MT}$ of a recording site, respectively. In (A-C), a white line with a black background in the bottom panel is a $p$-value by time function showing statistical significance of the difference between the total changes caused by individual and simultaneous applications of SS and CGP35348. and a disparity in the total effect of SS and Musc between simultaneous and individual drug applications existed over these intensities (Figure 10B).

The $\mathrm{GABA}_{\mathrm{B}}$ receptor agonist Bac was released individually and in combination with SS in seven cases, as shown by an example in Figure 11. Bac consistently suppressed the $\mathrm{D}_{\mathrm{N}}$ with or without the presence of SS. Difference waveforms indicated that the change caused by SS and Bac applied simultaneously was different from the sum of changes caused by the two drugs applied individually, suggesting that the drugs interacted with each other in regulating an LFP (Figures 11A,B right panels). The interaction between SS and Bac was observed over a wide range of frequencies and intensities (Figure 11B).
Results from individual cases indicated that SS and a GABAergic receptor agonist interacted with each other in regulating an LFP in the ICd. Depending on the relative strengths of the currents for releasing the drugs, the resulting waveform of $D_{N}$ can have a positive polarity or negative polarity or a change of polarity over time. Owing to the sensitivity of the waveform to currents, no statistical analysis was performed on the interaction between SS and a receptor agonist.

\section{DISCUSSION}

An understanding of the effect of SS on hearing is dependent on identification of target structures of the drug and evaluation of drug-induced changes in neural activity in the structures. 

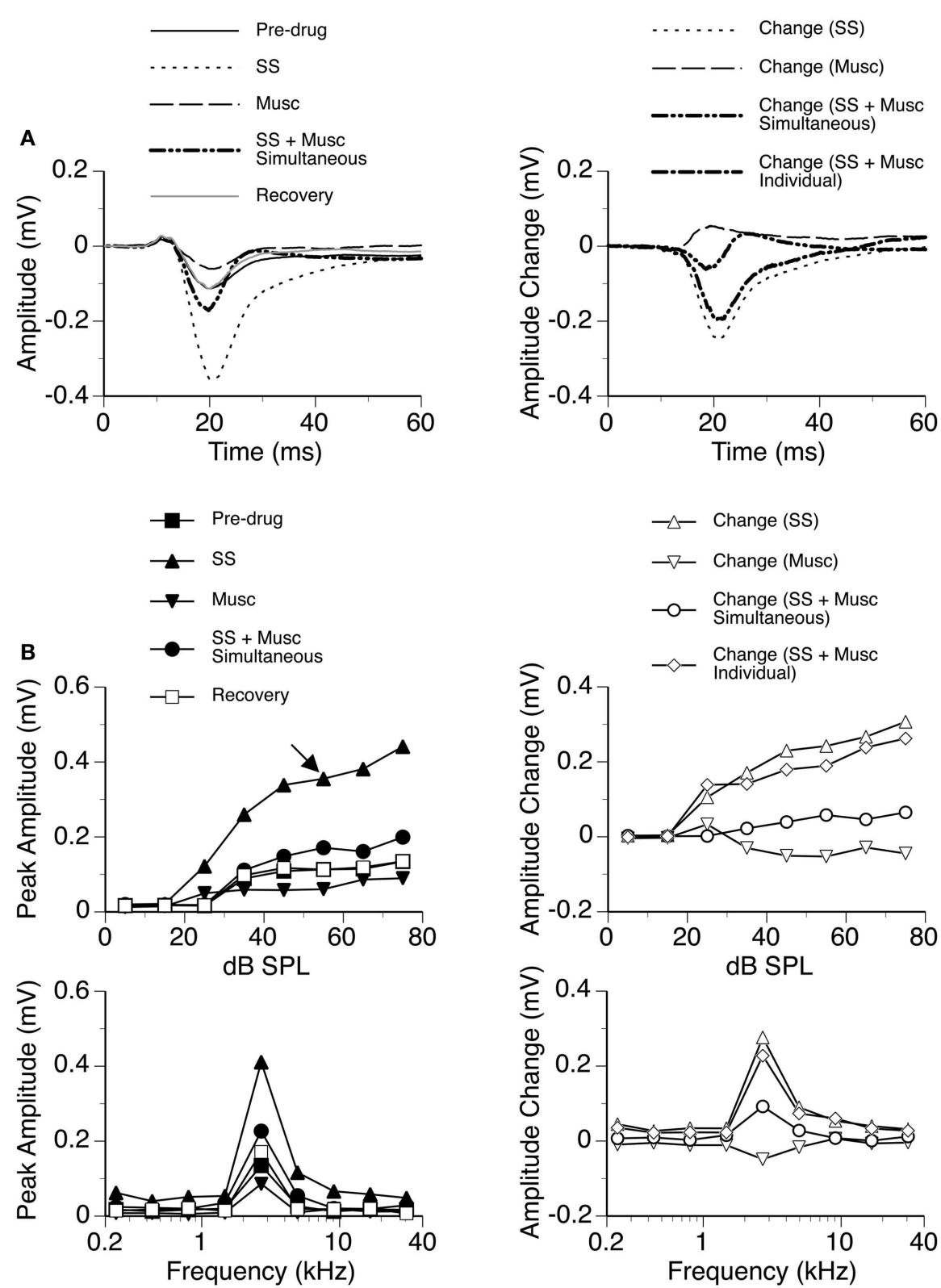

FIGURE 10 | An example showing the interaction between SS and Musc. (A) Left panel: LFPs evoked by a tone burst at the BF $(2.7 \mathrm{kHz})$ and $30 \mathrm{~dB}$ above the MT of the recording site las indicated by an arrow in the top left panel of (B)] before drug, during individual and simultaneous applications of SS and Musc, and after recovery. (A) Right panel: difference waveforms showing changes caused by individual and simultaneous applications of SS and Musc along with a waveform resulting from summation of changes caused by individual applications of the drugs. (B) Left panels: amplitude by

sound-pressure level (top) and amplitude by sound-frequency (bottom) functions obtained before drug, during individual and simultaneous applications of SS and Musc, and after recovery. (B) Right panels: changes in the peak amplitude of an LFP caused by individual and simultaneous applications of SS and Musc at various sound-pressure levels (top) and frequencies (bottom). Also, shown in each of the two panels is a curve resulting from summation of changes caused by individual applications of the drugs.

Furthermore, it is dependent on examination of the effect of the drug on neural mechanisms (e.g., neurotransmission) in the structures.

\section{IDENTIFICATION OF ICd AS A TARGET STRUCTURE OF SS}

Sodium salicylate reduces inputs to the central auditory system by suppressing electromotility of outer hair cells (23-26). However, systemic application of the drug does not change the amplitude of a sound-driven LFP in the IC $(22,27)$. This contrast suggests that the drug can directly target the IC and/or brainstem structure(s), enhancing the gain (i.e., the input-output relation) of the pathway from the cochlear nucleus to the IC (27). Such a change in neural activity offsets the reduction in the input to the central auditory system. 

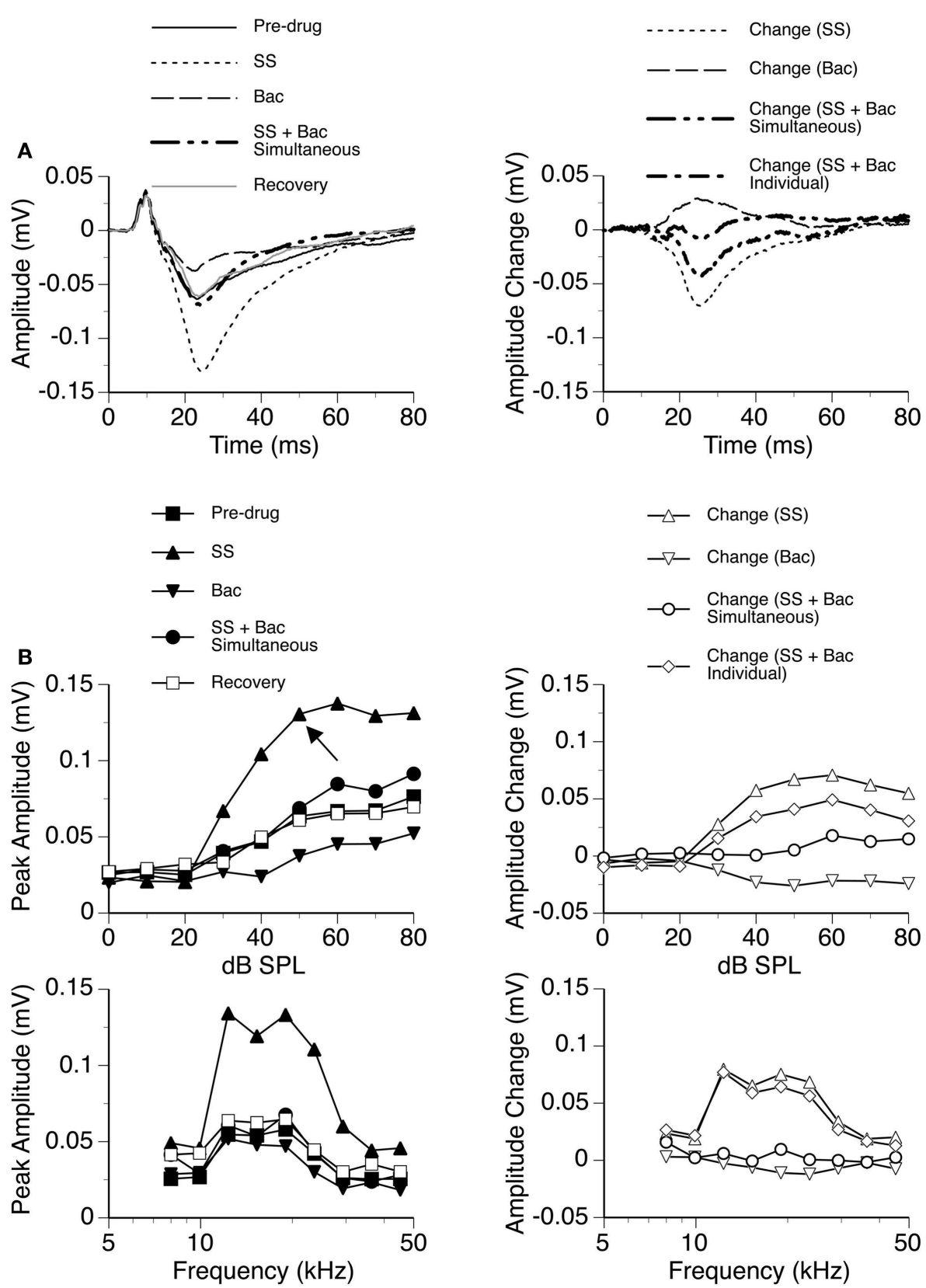

FIGURE 11 | An example showing the interaction between SS and Bac. (A) Left panel: LFPs evoked by a tone burst at the BF $(19.0 \mathrm{kHz})$ and $20 \mathrm{~dB}$ above the MT of the recording site [as indicated by an arrow in the top left panel of (B)] before drug, during individual and simultaneous applications of SS and Bac, and after recovery. (A) Right panel: difference waveforms showing changes caused by individual and simultaneous applications of SS and Bac. Also, shown in this panel is a waveform resulting from summation of changes caused by individual applications of SS and Bac. (B) Left panels:

amplitude by sound-pressure level (top) and amplitude by sound-frequency (bottom) functions obtained before drug, during individual and simultaneous applications of SS and Bac, and after recovery. (B) Right panels: changes in the peak amplitude of an LFP caused by individual and simultaneous applications of SS and Bac at various sound-pressure levels (top) and frequencies (bottom). Also, shown in each of the two panels is a curve resulting from summation of changes caused by individual applications of SS and Bac.

Using in vitro physiological recordings/pharmacological manipulations, people have identified the ICc and ICx as target structures of SS $(34,54)$. The same approach has also been used to find target structures of SS in the auditory forebrain $(33,55-$ 57). In the in vitro studies, circuits associated with a neuron under

investigation were only partially retained and inputs to the neuron were artificially activated. Therefore, it is difficult to use results from these studies to predict how local SS affects spontaneous and sound-driven activities of neurons in a live animal. An in vivo neurophysiological/pharmacological approach has been used to deal 
with this limitation. Using the in vivo approach, people have found that local SS in the AC can reduce spontaneous activity but enhance sound-driven activity in the structure (58). No results have been published about how local SS affects sound-driven activities in midbrain/brainstem structures.

In the present study, we recorded sound-evoked LFPs in the ICd while applying SS microiontophoretically at recording sites. Our results indicate that local SS can enhance auditory responses in the ICd. As SS is a small molecule that can cross blood-brain barrier, it is reasonable to believe that SS applied systemically can also reach the ICd and lead to an enhancement in auditory activity in the structure. As brain tissue is a volume conductor, an enhanced auditory response in the ICd caused by local SS can lead to an enhanced ensemble sound-driven response of the entire IC [e.g., an LFP recorded by Sun et al. (27)]. Such an enhancement can lead to an increase in the gain of the IC. It has yet to be determined whether local SS in the ICc and ICx can enhance auditory activities in the two subdivisions. Such enhancements could also lead to increases in the gain of the entire IC. A sound-driven LFP in the IC as an entity remains unchanged following systemic application of SS (27). Thus, an increase in the gain of the IC caused by local SS following systemic application of the drug should be accompanied by a reduction in the input to the structure. Further experiments are needed for evaluating the effect of SS on inputs to the IC.

An enhancement of auditory responses in the ICd by SS may cause secondary changes in the ICc and ICx through intrinsic projections (59-61). As excitatory/inhibitory natures of these projections are poorly understood, it is difficult to postulate whether auditory activities in the ICc and ICx are enhanced or suppressed. Elucidating secondary effects of SS can help fully understand the effect of the drug on the auditory midbrain.

A direct effect of SS on sound-driven LFPs in the ICd does not preclude the possibility that SS applied systemically can also enhance neural activity in the ICd through affecting sources of inputs to this structure. The ICd receives major inputs bilaterally from the AC $(59,62-67)$. Descending projections from the AC are likely excitatory in nature (68). An enhancement of auditory activity following systemic injection of SS has been observed in the $\operatorname{AC}(27,28,30,58,69,70)$. This enhancement can very likely be reflected in sound-driven responses in the ICd. SS may also affect auditory activity in the ICd through affecting activity in the ICc and ICx, which provide intrinsic projections to the ICd (5961). Knowledge about effects of SS on auditory responses in the ICc and ICx and information about excitatory/inhibitory natures of the intrinsic projections are needed for evaluating the dependence of auditory activity in the ICd on the ICc and ICx following systemic application of SS.

Technical limitations need to be taken into consideration in the interpretation of results from the present study. An LFP is a weighted average of potential changes generated by current dipoles at the vicinity of a recording electrode (71-73). Current dipoles located as far as a few hundred micrometers away from an electrode can contribute to an $\operatorname{LFP}(74,75)$. Owing to the close proximity of the ICd to an area in the ICc where neurons with low characteristic frequencies congregate, an LFP evoked by a lowfrequency sound recorded in the ICd may include contributions from these low-frequency ICc neurons. As neurons in the ICx are not tonotopically organized, a single tone burst unlikely activates many ICx neurons bordering the ICd. Therefore, contribution of the ICx to an LFP recorded in the ICd is likely limited. It is decent to believe that LFPs recorded in the present study were predominantly dependent on the ICd, in spite of possible contributions from the ICc (51).

\section{SS AND GABAergic NEUROTRANSMISSION IN THE ICd}

Our results reveal that simultaneous application of SS and a GABAergic receptor agonist or antagonist produces a change in the amplitude of an LFP different from the total change caused by the two drugs applied individually. These results suggest that SS can either directly or indirectly modulate GABAergic neurotransmission in the ICd.

Brain slice studies have revealed that SS can reduce the release of GABA in IC neurons. This reduction is at least partly due to suppression of serotonergic inputs to the GABAergic neurons (34). Such reduction can lead to disinhibition of neurons innervated by GABAergic projections. An SS-induced reduction in the release of GABA has also been observed in the AC. In this structure, SS can reduce activity of fast spiking interneurons (presumable inhibitory neurons releasing GABA) and suppress inhibitory postsynaptic currents in pyramidal neurons in layers II/III (neurons receiving GABAergic inputs) $(33,56)$.

Results from the present study suggest that SS can modulate GABAergic receptors. It is certain that sound-driven LFPs are different from postsynaptic potentials recorded from neurons in a brain slice preparations. However, it is believed that postsynaptic currents are among the most important current dipoles for generating an LFP (71-73, 76-78). Thus, a comparison of the time course of activation of a GABAergic receptor with the time window over which a synergistic interaction exists between SS and an antagonist of the receptor can provide useful information about the subtypes of receptors modulated by SS.

The interaction between BMI and SS was found between about 13.5 and $26 \mathrm{~ms}$ after the onset of a sound and was not dependent on the sound-pressure level. This time window is in general agreement with the time course of an inhibitory postsynaptic potential mediated by the $\mathrm{GABA}_{\mathrm{A}}$ receptor, which peaks at about $5 \mathrm{~ms}$ after activation of GABAergic inputs and has a halfwidth of about $23 \mathrm{~ms}$ (79).

The time window over which SS had a synergistic interaction with CGP35348 was from about $20 \mathrm{~ms}$ to about $27.6 \mathrm{~ms}$ after the onset of a sound at $10 \mathrm{~dB}$ above the MT and was wider at high-sound-pressure levels. This fact suggests that postsynaptic $\mathrm{GABA}_{\mathrm{B}}$ receptors are unlikely major targets of SS. Activation of such receptors by a single brief synaptic input can result in an inhibitory postsynaptic potential lasting for over $800 \mathrm{~ms}$ (80). Repetitive acoustic stimulation at a rate of $4 / \mathrm{s}$ (as used in the present study) would lead to sustained inhibition due to extensive temporal integration among individual postsynaptic potentials. Thus, application of SS and CGP35348 would have resulted in disinhibition over a much longer time window. Presynaptic $\mathrm{GABA}_{\mathrm{B}}$ receptors regulating the release of GABA are also unlikely major targets of SS. Suppression of these receptors by SS and CGP35348 would lead to a net inhibitory effect on postsynaptic neurons and a reduction in auditory activity. 
It is speculated that presynaptic $\mathrm{GABA}_{\mathrm{B}}$ receptors regulating the release of glutamate may have been affected by SS. Neurotransmitter receptors activated by glutamate include the $\alpha$-amino3-hydroxy-5-methyl-4-isoxazolepropionic acid (AMPA) receptor and the $N$-methyl-D-aspartate (NMDA) receptor. A postsynaptic potential mediated by the AMPA receptor peaks at about $5 \mathrm{~ms}$ after the activation of a glutamatergic input and has a halfwidth $<15 \mathrm{~ms}$, while a potential mediated by the NMDA receptor peaks at about $25 \mathrm{~ms}$ and has a larger halfwidth (79). The amplitude and duration of a potential mediated by the NMDA receptor are increased by depolarization of the cell membrane. Thus, similarities exist in the time course and level dependence between SS-CGP35348 synergistic interaction and NMDA receptor-mediated postsynaptic potentials. Such similarities suggest that the enhancement in sound-driven LFP during simultaneous application of SS and CGP35348 could be due to an increase in glutamate release and consequent enhancement in postsynaptic potentials mediated by NMDA receptors. This postulation needs to be tested by future neurophysiological/pharmacological experiments.

Our results do not rule out the possibility that the effect of SS on LFPs in the ICd may also be related to direct modulation of other neurotransmitter receptors and ion channels. In vitro studies in the IC indicate that SS can suppress glycine receptors with $\alpha 1$-subunits (81). In spiral ganglion neurons, aspirin can augment responses mediated by NMDA receptors (82). In the IC and AC, SS blocks voltage-gated sodium channels and L-type calcium channels (55, 83, 84). At high doses, SS or aspirin can inhibit acid-sensing ion channels (85). All these receptors and ion channels are possible targets of SS in the ICd.

EFFECTS OF SS: BEYOND GABAergic NEUROTRANSMISSION IN THE ICd Our results from the ICd strongly suggest that SS can enhance auditory responses through modulating local GABAergic receptors. It is likely that such modulation and a resulting enhancement in auditory response can occur beyond the ICd following systemic drug application, as GABAergic receptors also exist in other auditory structures (45-49). Enhancements of sound-driven LFPs have been found in the medial geniculate nucleus and the AC following systemic application of SS (22). Such enhancements are likely at least in part due to local modulation of GABAergic receptors.

Disinhibition in multiple structures in the auditory system may result in alterations in physiological characteristics of neural circuits. It is important to find whether reverberation of circuit and enhancement in synchronization among different auditory structures occur as a result of systemic SS application. A study of these alterations can help understand neurobiological bases of SS-induced hearing problems.

It has yet to be determined whether and how modification of GABAergic neurotransmission is responsible for SS-induced tinnitus. The relatively short-onset time of transient tinnitus (10) seems supporting that such a hearing disorder is related to direct modification of neural mechanisms. It is possible that SS-induced reduction in GABAergic inhibition not only enhances sounddriven responses (as revealed by our results) but also enables a neuron to fire action potentials in the event of receiving spontaneously generated synaptic inputs not associated with external acoustic stimuli. Such action potential firing may contribute to tinnitus.

As revealed by manganese-enhanced functional magnetic resonance imaging, expression of immediate early gene $c$-fos, and uptake of $\left[{ }^{14} \mathrm{C}\right]$ 2-deoxyglucose, chronic application of SS can induce tinnitus-like behavior along with a widespread increase in neural activity in the central auditory system (86-90). Structures showing a large increase in activity include the ICd. These changes caused by chronic application of SS may be in part due to direct modulation of GABAergic neurotransmission. They may also be due to alterations of other neural mechanisms, such as increase/reduction of the rate of receptor turnover and/or up/down regulation of the expression of receptor proteins. These homeostatic changes can cause side effects on hearing while helping reestablish the balance between excitation and inhibition tipped by SS.

\section{ACKNOWLEDGMENTS}

This research is supported by grants from the Natural Science and Engineering Research Council of Canada and the University of Windsor to Huiming Zhang. We thank Swetal Patel and PierrePaul Bitton for helping with the development of scripts used in the analysis of results.

\section{REFERENCES}

1. Cazals Y. Auditory sensori-neural alterations induced by salicylate. Prog Neurobiol (2000) 62:583-631. doi:10.1016/S0301-0082(00)00027-7

2. Gabriel SE, Fehring RA. Trends in the utilization of nonsteroidal antiinflammatory drugs in the United States, 1986-1990. J Clin Epidemiol (1992) 45:1041-4. doi:10.1016/0895-4356(92)90127-9

3. Henry JA, Roberts LE, Caspary DM, Theodoroff SM, Salvi RJ. Underlying mechanisms of tinnitus: review and clinical implications. J Am Acad Audiol (2014) 25:5-22. doi:10.3766/jaaa.25.1.2

4. Myers EN, Bernstein JM. Salicylate ototoxicity: a clinical and experimental study. Arch Otolaryngol (1965) 82:483-93. doi:10.1001/archotol.1965. 00760010485006

5. Stolzberg D, Salvi RJ, Allman BL. Salicylate toxicity model of tinnitus. Front Syst Neurosci (2012) 6:28. doi:10.3389/fnsys.2012.00028

6. Boettcher FA, Salvi RJ. Salicylate ototoxicity: review and synthesis. Am J Otolaryngol (1991) 12:33-47. doi:10.1016/0196-0709(91)90071-M

7. Brien JA. Ototoxicity associated with salicylates. A brief review. Drug Saf (1993) 9:143-8. doi:10.2165/00002018-199309020-00006

8. Grigor RR, Spitz PW, Furst DE. Salicylate toxicity in elderly patients with rheumatoid arthritis. J Rheumatol (1987) 14:60-6.

9. Halla JT, Hardin JG. Salicylate ototoxicity in patients with rheumatoid arthritis: a controlled study. Ann Rheum Dis (1988) 47:134-7. doi:10.1136/ard. 47.2.134

10. Mongan E, Kelly P, Nies K, Portor WW, Paulus HE. Tinnitus as an indication of therapeutic serum salicylate levels. JAMA (1973) 226:142-5. doi:10.1001/jama. 226.2.142

11. Samlan SR, Jordan MT, Chan SB, Wahl MS, Rubin RL. Tinnitus as a measure of salicylate toxicity in the overdose setting. West J Emerg Med (2008) 9:146-9.

12. Bauer CA, Brozoski TJ, Rojas R, Boley J, Wyder M. Behavioral model of chronic tinnitus in rats. Otolaryngol Head Neck Surg (1999) 121:457-62. doi:10.1016/S0194-5998(99)70237-8

13. Eggermont JJ. Hearing loss, hyperacusis, or tinnitus: what is modeled in animal research? Hear Res (2013) 295:140-9. doi:10.1016/j.heares.2012.01.005

14. Jastreboff PJ, Brennan JF, Coleman JK, Sasaki CT. Phantom auditory sensation in rats: an animal model for tinnitus. Behav Neurosci (1988) 102:811-22. doi:10.1037/0735-7044.102.6.811

15. Lobarinas E, Sun W, Cushing R, Salvi R. A novel behavioral paradigm for assessing tinnitus using schedule-induced polydipsia avoidance conditioning (SIP-AC). Hear Res (2004) 190:109-14. doi:10.1016/S03785955(04)00019-X 
16. Lobarinas E, Yang G, Sun W, Ding D, Mirza N, Dalby-Brown W, et al. Salicylateand quinine-induced tinnitus and effects of memantine. Acta Otolaryngol Suppl (2006) 556:13-9. doi:10.1080/03655230600895408

17. Rüttiger L, Ciuffani J, Zenner HP, Knipper M. A behavioral paradigm to judge acute sodium salicylate-induced sound experience in rats: a new approach for an animal model on tinnitus. Hear Res (2003) 180:39-50. doi:10.1016/S03785955(03)00075-3

18. Turner JG. Behavioral measures of tinnitus in laboratory animals. Prog Brain Res (2007) 166:147-56. doi:10.1016/S0079-6123(07)66013-0

19. Turner JG, Parrish J. Gap detection methods for assessing salicylate-induced tinnitus and hyperacusis in rats. Am J Audiol (2008) 17:S185-92. doi:10.1044/ 1059-0889(2008/08-0006)

20. Eggermont JJ, Roberts LE. The neuroscience of tinnitus. Trends Neurosci (2004) 27:676-82. doi:10.1016/j.tins.2004.08.010

21. Roberts LE, Eggermont JJ, Caspary DM, Shore SE, Melcher JR, Kaltenbach JA. Ringing ears: the neuroscience of tinnitus. J Neurosci (2010) 30:14972-9. doi:10.1523/JNEUROSCI.4028-10.2010

22. Sheppard A, Hayes SH, Chen G-D, Ralli M, Salvi R. Review of salicylate-induced hearing loss, neurotoxicity, tinnitus and neuropathophysiology. Acta Otorhinolarylgol Ital (2014) 34:79-93.

23. Liberman MC, Gao J, He DZ, Wu X, Jia S, Zuo J. Prestin is required for electromotility of the outer hair cell and for the cochlear amplifier. Nature (2002) 419:300-4. doi:10.1038/nature01059

24. Kakehata S, Santos-Sacchi J. Effects of salicylate and lanthanides on outer hair cell motility and associated gating charge. J Neurosci (1996) 16:4881-9.

25. Müller M, Klinke R, Arnold W, Oestreicher E. Auditory nerve fibre responses to salicylate revisited. Hear Res (2003) 183:37-43. doi:10.1016/S0378-5955(03) 00217-X

26. Zheng J, Shen W, He DZ, Long KB, Madison LD, Dallos P. Prestin is the motor protein of cochlear outer hair cells. Nature (2000) 405:149-55. doi:10.1038/ 35012009

27. Sun W, Lu J, Stolzberg D, Gray L, Deng A, Lobarinas E, et al. Salicylate increases the gain of the central auditory system. Neuroscience (2009) 159:325-34. doi:10.1016/j.neuroscience.2008.12.024

28. Yang G, Lobarinas E, Zhang L, Turner J, Stolzberg D, Salvi R, et al. Salicylate induced tinnitus: behavioral measures and neural activity in auditory cortex of awaken rats. Hear Res (2007) 226:244-53. doi:10.1016/j.heares.2006.06.013

29. Chen GD, Jastreboff PJ. Salicylate-induced abnormal activity in the inferior colliculus of rats. Hear Res (1995) 82:158-78. doi:10.1016/0378-5955(94)00174-O

30. Eggermont JJ, Kenmochi M. Salicylate and quinine selectively increase spontaneous firing rates in secondary auditory cortex. Hear Res (1998) 117:149-60. doi:10.1016/S0378-5955(98)00008-2

31. Jastreboff PJ, Sasaki CT. Salicylate-induced changes in spontaneous activity of single units in the inferior colliculus of the guinea pig. J Acoust Soc Am (1986) 80:1384-91. doi:10.1121/1.394391

32. Gong N, Zhang M, Zhang XB, Chen L, Sun GC, Xu TL. The aspirin metabolite salicylate enhances neuronal excitation in rat hippocampal CA1 area through reducing GABAergic inhibition. Neuropharmacology (2008) 54:454-63. doi:10.1016/j.neuropharm.2007.10.017

33. Wang HT, Luo B, Zhou KQ, Xu TL, Chen L. Sodium salicylate reduces inhibitory postsynaptic currents in neurons of rat auditory cortex. Hear Res (2006) 215:77-83. doi:10.1016/j.heares.2006.03.004

34. Wang HT, Luo B, Huang YN, Zhou KQ, Chen L. Sodium salicylate suppresses serotonin-induced enhancement of GABAergic spontaneous inhibitory postsynaptic currents in rat inferior colliculus in vitro. Hear Res (2008) 236:42-51. doi:10.1016/j.heares.2007.11.015

35. Xu H, Gong N, Chen L, Xu TL. Sodium salicylate reduces gamma aminobutyric acid-induced current in rat spinal dorsal horn neurons. Neuroreport (2005) 16:813-6. doi:10.1097/00001756-200505310-00007

36. Faingold CL, Gehlbach G, Caspary DM. On the role of GABA as an inhibitory neurotransmitter in inferior colliculus neurons - iontophoretic studies. Brain Res (1989) 500:302-12. doi:10.1016/0006-8993(89)90326-0

37. Fussesery ZM, Hall JC. Role of GABA in shaping frequency tuning and creating FM sweep selectivity in the inferior colliculus. J Neurophysiol (1996) 76:1059-73.

38. Zhang H, Kelly JB. Glutamatergic and GABAergic regulation of neural responses in inferior colliculus to amplitude-modulated sounds. J Neurophysiol (2003) 90:477-90. doi:10.1152/jn.01084.2002
39. Zhang H, Xu J, Feng AS. Effects of GABA-mediated inhibition on directiondependent frequency tuning in the frog inferior colliculus. J Comp Physiol A (1999) 184:86-98. doi:10.1007/s003590050308

40. Ma WL, Hidaka H, May BJ. Spontaneous activity in the inferior colliculus of CBA/J mice after manipulations that induce tinnitus. Hear Res (2006) 212:9-21. doi:10.1016/j.heares.2005.10.003

41. Adams JC, Wenthold RJ. Distribution of putative amino acid transmitters, choline acetyltransferase and glutamate decarboxylase in the inferior colliculus. Neuroscience (1979) 4:947-51. doi:10.1016/0306-4522(79)90067-8

42. Kelly JB, Caspary DM. Pharmacology of the inferior colliculus. In: Winer JA, Schreiner CE, editors. The Inferior Colliculus. New York, NY: Springer (2005). p. 248-81.

43. Merchán M, Aguilar LA, Lopez-Poveda EA, Malmierca MS. The inferior colliculus of the rat: quantitative immunocytochemical study of GABA and glycine. Neuroscience (2005) 136:907-25. doi:10.1016/j.neuroscience.2004.12.030

44. Vater M, Kössl M, Horn AK. GAD- and GABA-immunoreactivity in the ascending auditory pathway of horseshoe and mustached bats. J Comp Neurol (1992) 325:183-206. doi:10.1002/cne.903250205

45. Bowery NG, Hudson AL, Price GW. GABA A and $G_{A B A}$ receptor site distribution in the rat central nervous system. Neuroscience (1987) 20:365-83. doi:10.1016/0306-4522(87)90098-4

46. Fubara BM, Casseday JH, Covey E, Schwartz-Bloom RD. Distribution of GABA $\mathrm{GABA}_{\mathrm{B}}$, and glycine receptors in the central auditory system of the big brown bat, Eptesicus fuscus. J Comp Neurol (1996) 369:83-92. doi:10.1002/(SICI) 10969861(19960520)369:1<83::AID-CNE6>3.0.CO;2-G

47. Glendening KK, Baker BN. Neuroanatomical distribution of receptors for three potential inhibitory neurotransmitters in the brainstem auditory nuclei of the cat. J Comp Neurol (1988) 275:288-308. doi:10.1002/cne.902750210

48. Jamal L, Zhang H, Finlayson PG, Porter LA, Zhang H. The level and distribution of the $\mathrm{GABA}_{\mathrm{B}} \mathrm{R} 2$ receptor subunit in the rat's central auditory system. Neuroscience (2011) 181:243-56. doi:10.3389/fncir.2012.00092

49. Jamal L, Khan AN, Butt S, Patel CR, Zhang H. The level and distribution of the $\mathrm{GABA}_{\mathrm{B}} \mathrm{R} 1$ and $\mathrm{GABA}_{\mathrm{B}} \mathrm{R} 2$ receptor subunit in the rat's inferior colliculus. Front Neurosci (2012) 6:92. doi:10.3389/fncir.2012.00092

50. Milbrandt JC, Albin RL, Caspary DM. Age-related decrease in $\mathrm{GABA}_{B}$ receptor binding in the Fischer 344 rat inferior colliculus. Neurobiol Aging (1994) 15:699-703. doi:10.1016/0197-4580(94)90051-5

51. Patel CR, Redhead C, Cervi AL, Zhang H. Neural sensitivity to novel sounds in the rat's dorsal cortex of the inferior colliculus as revealed by evoked local field potentials. Hear Res (2012) 286:41-54. doi:10.1016/j.heares.2012.02.007

52. Lumani A, Zhang H. Responses of neurons in the rat's dorsal cortex of the inferior colliculus to monaural tone bursts. Brain Res (2010) 1351:115-29. doi:10.1016/j.brainres.2010.06.066

53. Slinker BK. The statistics of synergism. J Mol Cell Cardiol (1998) 30:723-31. doi:10.1006/jmcc. 1998.0655

54. Basta D, Ernst A. Effects of salicylate on spontaneous activity in inferior colliculus brain slices. Neurosci Res (2004) 50:237-43. doi:10.1016/j.neures.2004. 07.003

55. Liu Y, Zhang H, Li X, Wang Y, Lu H, Qi X, et al. Inhibition of voltage-gated channel currents in rat auditory cortex neurons by salicylate. Neuropharmacology (2007) 53:870-80. doi:10.1016/j.neuropharm.2007.08.015

56. Su Y-Y, Luo B, Wang HT, Chen L. Differential effects of sodium salicylate on current-evoked firing of pyramidal neurons and fast-spiking interneurons in slices of rat auditory cortex. Hear Res (2009) 253:60-6. doi:10.1016/j.heares. 2009.03.007

57. Su Y-Y, Luo B, Jin Y, Wu SH, Lobarinas E, Salvi RJ, et al. Altered neuronal intrinsic properties and reduced synaptic transmission of the rat's media geniculate body in salicylate-induced tinnitus. PLoS One (2012) 7(10):e46969. doi:10.1371/journal.pone.0046969

58. Lu J, Lobarinas E, Deng A, Goodey R, Stolzberg D, Salvi RJ, et al. GABAergic neural activity involved in salicylate-induced auditory cortex gain enhancement. Neuroscience (2011) 189:187-98. doi:10.1016/j.neuroscience.2011.04.073

59. Coleman JR, Clerici WJ. Sources of projections to subdivisions of the inferior colliculus in the rat. J Comp Neurol (1987) 262:215-26. doi:10.1002/cne. 902620204

60. González-Hernández TH, Meyer G, Ferres-Torres R. The commissural interconnections of the inferior colliculus in the albino mouse. Brain Res (1986) 368:268-76. doi:10.1016/0006-8993(86)90571-8 
61. Malmierca MS, Hernandez O, Falconi A, Merchan M, Rees A. The commissure of the inferior colliuclus, anatomical and physiological correlates. Assoc Res Otolaryngol Abstr (2001) 24:191.

62. Bajo VM, Nodal FR, Bizley JK, Moore DR, King AJ. The ferret auditory cortex: descending projections to the inferior colliculus. Cereb Cortex (2007) 17:475-91. doi:10.1093/cercor/bhj164

63. Druga R, Syka J, Rajkowska G. Projections of auditory cortex onto the inferior colliculus in the rat. Physiol Res (1997) 46:215-22.

64. Herbert H, Aschoff A, Ostwald J. Topography of projections from the auditory cortex to the inferior colliculus in the rat. J Comp Neurol (1991) 304:103-22. doi: $10.1002 /$ cne. 903040108

65. Herrera M, Hurtado-García JF, Collia F, Lanciego J. Projections from the primary auditory cortex onto the dorsal cortex of the inferior colliculus in albino rats. Arch Ital Biol (1994) 132:147-64.

66. Malmierca MS, Ryugo DK. Descending connections of auditory cortex to the midbrain and brain stem. In: Winer JA, Schreiner CE, editors. The Auditory Cortex. New York, NY: Springer (2010). p. 189-208.

67. Saldaña E, Feliciano M, Mugnaini E. Distribution of descending projections from primary auditory neocortex to inferior colliculus mimics the topography of intracollicular projections. J Comp Neurol (1996) 371:15-40. doi:10.1002/ (SICI) 1096-9861(19960715)371:1<15::AID-CNE2>3.0.CO;2-O

68. Feliciano M, Potashner SJ. Evidence for a glutamatergic pathway from the guinea pig auditory cortex to the inferior colliculus. J Neurochem (1995) 65:1348-57. doi:10.1046/j.1471-4159.1995.65031348.x

69. Norena AJ, Moffat G, Blanc JL, Pezard L, Cazals Y. Neural changes in the auditory cortex of awake guinea pigs after two tinnitus inducers: salicylate and acoustic trauma. Neuroscience (2010) 166:1194-209. doi:10.1016/j.neuroscience.2009. 12.063

70. Zhang X, Yang P, Cao Y, Qin L, Sato Y. Salicylate induced neural changes in the primary auditory cortex of awake cats. Neuroscience (2011) 172:232-45. doi:10.1016/j.neuroscience.2010.10.073

71. Logothetis NK. The underpinnings of the BOLD functional magnetic resonance imaging signal. J Neurosci (2003) 23:3963-71.

72. Logothetis NK. What we can do and what we cannot do with fMRI. Nature (2008) 453:869-78. doi:10.1038/nature06976

73. Goense JB, Logothetis NK. Neurophysiology of the BOLD fMRI signal in awake monkeys. Curr Biol (2008) 18:631-40. doi:10.1016/j.cub.2008.03.054

74. Freeman WJ. Mass Action in the Nervous System. New York, NY: Academic Press (1975).

75. Legatt AD, Arezzo J, Vaughan HG. Averaged multiple unit activity as an estimate of phasic changes in local neuronal activity: effect of volume-conducted potentials. J Neurosci Methods (1980) 2:203-17. doi:10.1016/0165-0270(80) 90061-8

76. Burkard RF, Secor CA, Salvi RJ. Near-field responses from the round window, inferior colliculus, and auditory cortex of the unanesthetized chinchilla: manipulations of noiseburst level and rate. J Acoust Soc Am (1999) 106:304-31. doi:10.1121/1.427058

77. Mitzdorf U. Current source-density method and application in cat cerebral cortex: investigation of evoked potentials and EEG phenomena. Physiol Rev (1985) 65:37-100.

78. Mitzdorf U. Properties of the evoked potential generators: current sourcedensity analysis of visually evoked potentials in the cat cortex. Int J Neurosci (1987) 33:33-59. doi:10.3109/00207458708985928

79. Wu SH, Ma CL, Kelly JB. Contribution of AMPA, NMDA, and GABAA receptors to temporal pattern of postsynaptic responses in the inferior colliculus of the rat. J Neurosci (2004) 24:4625-34. doi:10.1523/JNEUROSCI.0318-04.2004
80. Sun $\mathrm{H}, \mathrm{Wu} \mathrm{SH}$. The physiological role of pre- and postsynaptic GABA(B) receptors in membrane excitability and synaptic transmission of neurons in the rat's dorsal cortex of the inferior colliculus. Neuroscience (2009) 21:198-211. doi:10.1016/j.neuroscience.2009.02.011

81. Lu YG, Tang ZQ, Ye ZY, Wang HT, Huang YN, Zhou KQ, et al. Salicylate, an aspirin metabolite, specifically inhibits the current mediated by glycine receptors containing alphal-subunits. Br J Pharmacol (2009) 157:1514-22. doi:10.1111/j.1476-5381.2009.00321.x

82. Peng BG, Chen S, Lin X. Aspirin selectively augmented N-methyl-D-aspartate types of glutamate responses in cultured spiral ganglion neurons of mice. $\mathrm{Neu}$ rosci Lett (2003) 343:21-4. doi:10.1016/S0304-3940(03)00296-9

83. Liu Y, Li X. Effects of salicylate on voltage-gated sodium channels in rat inferior colliculus neurons. Hear Res (2004) 193:68-74. doi:10.1016/j.heares.2004. 03.006

84. Liu Y, Li X, Ma C, Liu J, Lu H. Salicylate blocks L-type calcium channels in rat inferior colliculus neurons. Hear Res (2005) 205:271-6. doi:10.1016/j.heares. 2005.03.028

85. Wang W, Ye SD, Zhou KQ, Wu LM, Huang YN. High doses of salicylate and aspirin are inhibitory on acid-sensing ion channels and protective against acidosis-induced neuronal injury in the rat cortical neuron. J Neurosci Res (2012) 90:267-77. doi:10.1002/jnr.22742

86. Holt AG, Bissig D, Mirza N, Rajah G, Berkowitz B. Evidence of key tinnitusrelated brain regions documented by a unique combination of manganeseenhanced MRI and acoustic startle reflex testing. PLoS One (2010) 5:e14260. doi:10.1371/journal.pone.0014260

87. Wallhausser-Franke E. Salicylate evokes c-fos expression in the brain stem: implications for tinnitus. Neuroreport (1997) 8:725-8. doi:10.1097/00001756199702100-00029

88. Wallhausser-Franke E, Braun S, Langner G. Salicylate alters 2-DG uptake in the auditory system: a model for tinnitus? Neuroreport (1995) 7:1585-8. doi:10.1097/00001756-199607080-00010

89. Wallhausser-Franke E, Mahlke C, Oliva R, Braun S, Wenz G, Langner G. Expression of c-fos in auditory and non-auditory brain regions of the gerbil after manipulations that induce tinnitus. Exp Brain Res (2003) 153:649-54 doi:10.1007/s00221-003-1614-2

90. Wu JL, Chiu TW, Poon PW. Differential changes in Fos-immunoreactivity at the auditory brainstem after chronic injections of salicylate in rats. Hear Res (2003) 176:80-93. doi:10.1016/S0378-5955(02)00747-5

Conflict of Interest Statement: The authors declare that the research was conducted in the absence of any commercial or financial relationships that could be construed as a potential conflict of interest.

Received: 26 August 2014; paper pending published: 26 September 2014; accepted: 30 October 2014; published online: 14 November 2014.

Citation: Patel CR and Zhang H (2014) Local application of sodium salicylate enhances auditory responses in the rat's dorsal cortex of the inferior colliculus. Front. Neurol. 5:235. doi: 10.3389/fneur.2014.00235

This article was submitted to Neuro-otology, a section of the journal Frontiers in Neurology.

Copyright (C) 2014 Patel and Zhang. This is an open-access article distributed under the terms of the Creative Commons Attribution License (CC BY). The use, distribution or reproduction in other forums is permitted, provided the original author(s) or licensor are credited and that the original publication in this journal is cited, in accordance with accepted academic practice. No use, distribution or reproduction is permitted which does not comply with these terms. 